\title{
Adult Nurse Practitioner
}

National Cancer Institute

\section{Source}

National Cancer Institute. Adult Nurse Practitioner. NCI Thesaurus. Code C71283.

A registered nurse prepared in a graduate level adult nurse practitioner program to provide a full range of health care services on the wellness-illness health care continuum at an advanced level to adults. 